\title{
The correlation between telecommunications and economic development: The essential connection
}

\author{
Greg Borduas, Ec.D.
}

\begin{abstract}
Much has been written, discussed, debated, advertised and hypothesized about the knowledge-based economy, the need for speed and the effect of the internet on the economy in general. This overwhelming information exchange and speed of change has had a profound effect on the economic development mandate at a variety of levels in the public and private sector. This paper examines the synergies between economic development and telecommunications in rural and urban environments, concluding that in rural settings its impact on economic development has the potential to create significant benefits.
\end{abstract}

Keywords: telecommunications, economic development, knowledge-based economy

Much has been written, discussed, debated, advertised and hypothesized about the knowledgebased economy, the need for speed and the effect of the internet on the economy in general. This overwhelming information exchange and speed of change has had a profound effect on the economic development mandate at a variety of levels in the public and private sector.

As the knowledge based economy grows exponentially, the impact on communities and various levels of public and private sector economic development programs has presented challenges to those practitioners responsible for delivering services.

The synergies between economic development and telecommunications are becoming clearer. The co-relationship and inter-dependence of economic development and telecommunications readiness by those charged with delivering both is converging at a rapid pace.

\section{Telecommunications as an economic enabler}

"Combined with other information technologies, telecommunications makes substantial enabling conditions to the economy and to the social well being far beyond its direct contributions in employment and GDP growth. Progress in moving the telecommunications sector forward creates a positive impact on education, health care, industrial productivity and competitiveness, economic development, government efficiency and budget deficits" (Davidson \& Hubert, 1994). 
Deregulation in the telecommunications industry in the Canadian marketplace has occurred on two major fronts over the past five years - the deregulation of the long distance market and deregulation of local telephone service. The result has been a drastic price reduction in long distance services (three to ten cents per minute) and new entrants to the marketplace. Customers can now select from a variety of suppliers for their long distance, cellular, internet and local access requirements. Consequently, economic development activity by Canadian and US based firms at the local level has intensified.

Communities have been directly exposed to the explosion of high technology and telecommunications activity. In Canada, the explosion has occurred in communities with strong ties between industry and post-secondary education institutions. Communities such as the Ottawa region, and the Kitchener/Waterloo/Cambridge region have seen tremendous economic activity in the high tech sector primarily as a result of the partnerships created between the private and public sectors.

In Ottawa, a non-for-profit entity, the Ottawa Centre for Research and Innovation (OCRI) was created to further the high tech sector in the region. In 2001, after seventeen years of existence, OCRI boasts membership in excess of 600 members of the Ottawa high tech community. Members include large corporations, research laboratories, small and medium sized technology companies, post-secondary academic institutions, school boards, regional government and private individuals.

The mandate for OCRI is to build on the strengths of the Ottawa region to advance research and development, lifelong learning, professional development and community infrastructure. OCRI's Board of Directors is comprised of 25 top technology professionals representing many of the world's leading high tech firms located in the Ottawa region.

A recent achievement of OCRI, was their being selected by Industry Canada, as part of Ontario's Smart Communities Demonstration Project. Sm@rtCapital is an initiative of OCRI which is designed to accelerate the development of online services for all sectors of the community of Ottawa.

The Kitchener/Waterloo/Cambridge region has adopted the moniker "Canada's Technology Triangle" (CTT). The three cities - Kitchener, Waterloo and Cambridge - and the Region of Waterloo have created a non-for-profit corporation, Canada's Technology Triangle (CTT), to act as an umbrella organization in providing leadership for national and international investment attraction activities. 
Each of the three cities continue to maintain economic development departments that offer local complementary services to CTT such as marketing, downtown revitalization and investment retention activities.

The high tech sector in CTT has been successful in creating private public partnerships in support of the needs of the local knowledge based economy. Communitech, a non-for-profit association was established in 1997 to be the collective voice of the CTT high tech community. The association has grown to exceed 225 members and "focuses the strengths and influence of its community on issues that impact the technology community and the continued development of critical mass within the technology industry (Communitech 2001)."

\section{Agent of change}

"By facilitating information flows, telecommunications may also generate new and improved communications within and between organizations. Additional market intelligence can mean higher sales for businesses, whereas both private and public organizations can benefit from more effective communications and associated gains in administrative and managerial performance. Telecommunications also provides the means for more efficient organizational structures, including decentralized locations for production, administration and service delivery functions" (Haney \& McCracken, 1997).

Telecommunications connectivity has provided "a new sales channel" for the delivery of products and services to consumers. Following the old adage "the customer comes first" or "the customer knows best", telecommunications connectivity has allowed companies to be open and accessible 24 hours a day, seven days a week. The customer can choose when, how and where to shop depending on their lifestyle. The company providing the service can significantly decrease transaction costs and improve productivity.

The banking industry has led the telecommunications connectivity charge through their applications including on line banking, automated teller services and tele-banking - all dependent on advances in telecommunications connectivity. High operational costs of small rural branches have given way to increased accessibility and productivity through connectivity by customers on a $7 \times 24$ basis.

Service Canada has led the way of changing the delivery of federal government services to Canadians. In Oxford County in rural Ontario, Service Canada has established a unique partnership with the County of Oxford Library Service. Customers seeking information on federal government services can access the web or visit the eleven information sites from the 
seventeen library branches across the County, to access electronically or in paper, hundreds of thousands of information items available from federal government departments.

The County of Oxford through the Community Access Program (CAP) offers public access computer workstations in each of its seventeen library branches to provide households without on line or internet capabilities electronic access to services.

\section{Connectivity versus location}

"Telecommunications can help to level the playing field on which rural and nonrural businesses compete - to overcome barriers which have limited the development of some rural communities in the past. Indeed, cases exist of how telecommunications is being used to maximize the use of local resources in rural areas, thereby promoting local economic benefits" (Haney \& McCracken, 1997).

The buzz words for industrial and commercial real estate have consistently been location, location, location; with companies paying premium prices per square foot for the privilege of leasing prime tenant space close to their customers.

Advances in telecommunications connectivity have almost entirely eliminated the location factor from the investment attraction equation. Traditional urban environments have given way to companies focusing on other location factors including quality of life considerations, leasing cost per square foot, employee turn-over rates, access to education and housing costs for employees. These other location factors combine to help level the playing field by which rural communities can compete for new investment.

Telecommunications connectivity has changed the site selection process from location specific to any location which has connectivity specifications required by the client.

Recent research in the US on trends in technology in rural communities has supported the North American notion that rural communities may have some decided advantages in the race for connectivity and that these areas may have competitive advantages in attracting business. The Insight Research Corporation, Parsippany, New Jersey conducted a research study in October 2000 that was recently reported in the June 2001 edition of Smart Business Magazine and listed the following trends in rural technology:

"Rural America could soon become a viable market for broadband services" (Tahmincioglu, 2001).

The following are highlights taken from the Insight Research's study: 
- farmers are more likely to have a PC at home than members of the general population;

- internet connections at rural area schools are more common than in urban schools;

- telecom competition is beginning to increase because more businesses, including ecommerce firms, are choosing to locate operations outside of cities to take advantage of lower land and labor costs;

- rural consumers tend to be aware of their neighbors telecommunications services, which means that if a telecommunications company comes in and starts offering broadband options, adoption will spread quickly"(Tahmincioglu, 2001).

Similar characteristics are evident in Canada. For instance, in Moore Township near Sarnia, Excell Global Services, a US based call centre corporation, established a directory assistance call centre in a former school house building. The initial business involved providing directory assistance for 1-800 customer information. In 1998, Excell Global Services partnered with Bell Canada's newly formed subsidiary, Bell Nordia to offer additional directory assistance services and significantly expanded employment at this location.

\section{Community capacity building}

"Telecommunications should not be used for the sole purpose of attracting business to rural locations, but also to augment development efforts towards improving those assets of a community which are attractive to current and potential residents and businesses, such as education, healthcare and other public service capacities" (US Congress, 1991).

"Successful teleconomic initiatives in rural areas often depend on the participation of a 'local champion', a visionary with strong leadership qualities, committed to using telecommunications in the pursuit of economic survival and prosperity" (Davidson \& Dibble 2001)

In New Brunswick, the provincial government created a series of partnerships with many private sector companies to foster the climate of connectivity readiness and to promote investment attraction.

The former Premier of New Brunswick, the Honourable Frank McKenna, provided the charismatic leadership to the driving force that produced the telecommunications revolution in New Brunswick. Premier McKenna met with North American private sector high tech community leaders and was the chief salesperson for investment attraction of high technology and knowledge-based economy firms to the province. 
A major partner to the telecommunications initiative was NBTel which invested heavily in telecommunications infrastructure across the province. New Brunswick became a leading North American jurisdiction in telecommunications infrastructure deployment in support of economic development investment attraction.

Hawarden, Iowa provides a case study of a successful, small rural municipal telecommunications connectivity initiative. This community with a population of approximately 2,400 persons created the Hawarden Integrated Technology, Energy and Communications (HITEC). HITEC was created as a municipal utility to offer cable television, telephone, internet, security, monitoring and fibre optics broadband services. This initiative was spearheaded by the local municipal council and has provided a significant telecommunications advantage in the community.

In reviewing research conducted on the relationship between economic development and telecommunications and in support of the issues addressed earlier in this paper, the following four observations are provided.

\section{Observation one: The seamless interrelationship}

Local economic development practices continue to evolve and increasingly involve a seamless interrelationship between economic development and telecommunications. The following statement sums up this activity and places a new meaning to economic development practices across North America:

\footnotetext{
"Some communities and regions have adopted economic development strategies that employ their telecommunications capabilities as a means of attracting business. Success stories of this form of 'teleconomic development' strategy are pervasive" (Haney \& McCracken, 1997).
}

A good example of a teleconomic development private-public strategy can be found in downtown San Diego where the Downtown San Diego Partnership and City Centre Development Corporation created Bandwidth Bay. Bandwidth Bay is an initiative to promote the telecommunications capability of downtown San Diego with several private sector commercial landlords. A web site has been created listing several commercial buildings for lease and their broadband capabilities.

\section{Observation two: Size doesn't matter}

Many Canadian and US communities are following a more proactive approach to understanding the dynamics of their local telecommunications capabilities and packaging and promoting these 
assets to attract potential investment opportunities. As noted in the previous examples, rural communities have succeeded in competing with their urban counterparts to promote knowledgebased investments in their communities. In fact, rural communities have had success in quantifying their telecommunications infrastructure for the purposes of retaining and attracting business opportunities.

"Many rural local exchange carriers (RLEC's) have a high-quality plant that is frequently rated by state commissions as among the best in their states" (Insight Research Corporation, 2000).

\section{Observation three: Communities are becoming connectivity wise}

"How did the Clampetts get so wired? The rural American economy is no longer strictly farm based, for starters. With a lower cost of living and an educated workforce, says Robert Rosenburg, president of Insight, 'businesses have begun locating call centres and distribution centres there in addition to manufacturing", (Tahmincioglu, 2001).

North American and, in particular Canadian communities, are becoming more and more connectivity wise. Access to major highway transportation systems and distance to markets have become less and less of a location issue in site selection and investment attraction. In fact, those unique places off the beaten track can represent viable locations for the knowledge-based business industry. Why set up shop in an urban centre where lease rates are steep, living costs are high and employee availability and turnover are major issues?

If you can set up shop in let's say Rubber Boot Junction (RBJ) for a fraction of the cost and all that is required for example, is the right connectivity - why not! It is the savvy promoters from places like RBJ that have been neglected for years who are quickly learning and marketing the capacity of connectivity in their communities. It is these people who are winning the day!

\section{Observation four: New community paradigms are being created}

Telecommunications is having a significant impact in creating new ideas, relationships and new paradigms in communities globally. Global clusters of like communities, industry alliances, cyber-partnerships and simple communications between individuals and organizations have become increasingly more available through advancements in telecommunications.

Planning a family reunion - send a world-wide email; hosting a community festival - set up an information web site; want a specific product from the Montreal distribution centre - request it from your desk over the company wide area network for delivery tomorrow. 
Telecommunications has provided a mechanism to bring individuals, communities, businesses, organizations and cultures together in a matter of milliseconds, and in the process, created dramatic paradigm shifts.

\section{Conclusion}

The synergies between economic development and telecommunications will continue to build over time. The importance of connectivity will take on new significance as improvements in technology occur and the types of applications mature over time.

The following statement adequately summarizes the major shifts and attitudes towards connectivity and telecommunications in rural and urban paradigms and the relative importance between economic development and telecommunications.

"The role of telecommunications is often much broader in the minds of those concerned about economic development in rural settings. When telecommunications is used to enhance public education, health care and other public services, and otherwise to improve the quality of rural life, its potential contribution to economic development is much greater (Haney \& McCracken, 1997)."

\section{Author biography}

Greg Borduas has held a series of positions in the private and public sectors primarily focusing on economic development and telecommunications.

Greg received his education at the University of Western Ontario and completed his economic development professional designation (Ec.D.), Certificate and Diploma at the University of Waterloo. His work experience has focused primarily on economic development and telecommunications practices in small to medium sized rural communities. During his tenure with Bell Canada, Greg created and launched the Bell Canada Economic Development Fund, the first private sector utility driven economic development fund in Canada.

Greg has lectured at numerous conferences and workshops on economic development and telecommunications practices. He is a Past President of the Economic Developers Council of Ontario (EDCO) and currently serves as the member representing Ontario on the Board of Directors of the Economic Developers Association of Canada (EDAC). 


\section{Bibliography}

Bandwidth Bay. Downtown San Diego, Accessed from www.bandwidthbay.org, May 2001.

Canada's Technology Triangle (CTT). Accessed from www.techtriangle.com, May 2001.

Communitech, Accessed from www.communitech.org. May 2001.

County of Oxford Library Service. Accessed from www.ocl.net, May 2001.

Davidson, W. and A. Dibble, "The Rural Challenge", Telephony, Vol. 220, No. 11, 1991.

Davidson, W. and R. Hubert, A Telecommunications Infrastructure: Enabling a New Future for Canada, a report for Northern Telecom, 1994.

Haney, M. and M. McCracken, The Effects of Improved Telephone Services on Regional Economies, a report for Bell Canada, 1997.

ICMA University Best Practices Symposium, Cedar Falls and Hawarden, Iowa Municipal Telecommunications Utilities Case Study, Dallas, Texas, 1999.

Insight Research Corporation. The Rural Telecom Consumer and Broadband Access 2000-2004, Parsippany, New Jersey, Accessed from www.insight-corp.com/rural.html. October 2000.

Ottawa Centre for Research and Innovation (OCRI). Accessed from www.ocri.com, May 2001.

Tahmincioglu, E., "Far from the Maddening Crowd", Smart Business Magazine, p. 48, San Francisco, California, 2001.

US Congress, Office of Technology Assessment, Rural America at the Crossroads, Networking for the Future, OTA-TCT-471, Washington, DC., 1991. 